\title{
Characterization of Carbon Nanotubes Loaded with Nitrogen, Phosphorus and Potassium Fertilizers
}

\author{
Mohammed Nagib Abdel-Ghany Hasaneen, Heba Mahmoud Mohammad Abdel-Aziz ${ }^{*}$, \\ Aya Moheb Omer
}

Department of Botany, Faculty of Science, Mansoura University, Mansoura, Egypt

Email address:

hebammabdelaziz@mans.edu.eg (H. M. M. Abdel-Aziz)

${ }^{*}$ Corresponding author

\section{To cite this article:}

Mohammed Nagib Abdel-Ghany Hasaneen, Heba Mahmoud Mohammad Abdel-Aziz, Aya Moheb Omer. Characterization of Carbon Nanotubes Loaded with Nitrogen, Phosphorus and Potassium Fertilizers. American Journal of Nano Research and Applications.

Vol. 5, No. 2, 2017, pp. 12-18. doi: 10.11648/j.nano.20170502.11

Received: February 26, 2017; Accepted: April 7, 2017; Published: May 2, 2017

\begin{abstract}
Carbon nanotubes either single-walled or multiwalled have been a focus in materials research. Carbon nanotubes are tubular structures of nanometer diameter and large length/diameter ratio. The nanotubes may consist of one, tens and hundreds of concentric shells of carbons with adjacent shells separation of $\sim 0.34 \mathrm{~nm}$ and they can have different individual structures, morphologies and properties. Hence, a wide variety of synthetic methods have been developed to produce the desired materials and properties for scientific studies or technological applications. In this study we succeeded to develop a chemical synthetic method that allows us to prepare carbon nanotubes (CNTs) from graphite powder easily and inexpensively at low temperatures (below $70^{\circ} \mathrm{C}$ ) and without applying pressure.
\end{abstract}

Keywords: Carbon Nanotubes, Fertilizer, Synthesis, Zeta Potentials, Infra-red Spectroscopy

\section{Introduction}

Carbon nanotubes (CNTs) are tubular structures that are typically of nanometer diameter and many micrometres in length, consist of a single layered cylinder which known as single walled carbon nanotubes (SWCNTs); or it may contain multiple concentric shells of carbons with adjacent shells separation of $0.34 \mathrm{~nm}$ and large length/diameter ratio which known as multi-walled carbon nanotubes (MWCNTs) [1]. Diameters of SWCNTs are typically between 0.8 to $2 \mathrm{~nm}$ and MWCNTs are 5 to $30 \mathrm{~nm}$, although MWCNTs diameters can exceed $100 \mathrm{~nm}$. This fascinating new class of materials was first observed by Endo [2], and later by Iijima [3] in the soot produced in the arc-discharge synthesis of fullerenes.

Carbon nanotubes (CNTs) are used in many fields such as optics, mechanics, electronics and biology. Carbon nanotubes (CNTs) have three shapes; chiral, zigzag, or armchair. Single walled carbon nanotubes may be in all three forms, while multiwalled CNTs exhibit only the armchair or zigzag.

The methods for the synthesis of CNTs can be divided into three types: laser ablation method, arc discharge and chemical vapor deposition method (CVD) [4]. The Chemical
Vapor Deposition (CVD) is the most appropriate method for synthesizing of CNTs with controlled diameter, length and number of walls [5]. It involves the decomposition of a gaseous or volatile compound of carbon, catalyzed by metallic nanoparticles [6]; both MWNT and SWNT synthesis have been well developed using CVD. However, the process of carbon nanotubes synthesis remains cost and difficult as the high temperatures and pressures are required.

CNTs can act as a nutrient carriers as in nanofertilizers which their dimensions ranging from 30 to $40 \mathrm{~nm}$ and capable of holding bountiful of nutrient ions due to their high surface area and release it slowly and steadily that commensurate with crop demand [7]. The application of nanofertilizers consists of $\mathrm{N}, \mathrm{P}, \mathrm{K}$ and micronutrients enhance the uptake and use of nutrients by grain crops [8].

The aim of this article is to provide a chemical synthesis which allows us to prepare CNTs easily and inexpensively either alone or loaded with NPK at low temperature without applying any pressure. 


\section{Materials and Methods}

\subsection{Materials and Chemicals}

Graphite powder (Purity $>99.99 \%$ ) was obtained from Sigma Aldrich, Germany. potassium chlorate $\left(\mathrm{KClO}_{3}\right)$, nitric acid $\left(\mathrm{HNO}_{3}\right)$ and sulfuric acid $\left(\mathrm{H}_{2} \mathrm{SO}_{4}, 99.9 \%\right)$, Calcium phosphate $\left(\mathrm{Ca}\left(\mathrm{H}_{2} \mathrm{PO}_{4}\right)_{2} \cdot \mathrm{H}_{2} \mathrm{O}\right)$, urea $\left(\mathrm{CO}\left(\mathrm{NH}_{2}\right)_{2}\right)$ and potassium chloride $(\mathrm{KCl})$ were obtained from different local manufacturers and suppliers.

\subsection{Preparation of Carbon Nanotubes}

$5 \mathrm{~g}$ of graphite powder was slowly added to a mixture of fuming $25 \mathrm{~cm}^{3}$ nitric acid and $50 \mathrm{~cm}^{3}$ sulfuric acid and stirred for 30 minutes. Then, the mixture was cooled at $5^{\circ} \mathrm{C}$ in an ice bath, about $25 \mathrm{~g}$ of potassium chlorate was added slowly to the previous solution with stirring for 30 minutes. The solution was then heated at $70^{\circ} \mathrm{C}$ for 24 hours and then placed in the air for three days. The floating graphite carbons were rinsed with $1000 \mathrm{~cm}^{3}$ deionized water, stirred for 1 hour, filtrated and the sample then was dried [9].

\subsection{Loading of NPK Fertilizer in Carbon Nanotubes}

Urea, calcium phosphate and potassium chloride were used as sources of N, P and K, respectively. The loading of NPK fertilizers on carbon nanotubes surface was obtained by dissolving about $0.2 \mathrm{~g}$ of $\mathrm{N}, 0.05 \mathrm{~g}$ of $\mathrm{P}$ and $0.2 \mathrm{~g}$ of $\mathrm{K}$ into 50 $\mathrm{cm}^{3}$ of carbon nanotubes solution for $6 \mathrm{~h}$ at room temperature [10].

\subsection{Characterization of the CNTs and CNTs Loaded with NPK}

\subsubsection{Ultrastructural Studies Using Transmission Electron Microscope (TEM)}

The morphology and size of the CNTs and CNTs- NPK were investigated using a JEOL 1010 transmission electron microscope at $80 \mathrm{kV}$ (JEOL, Mansoura University). CNTs solution was sonicated for 2 minutes to produce better particle dispersion and to prevent the nanotubes accumulation on the copper grid. One drop of the solution was spread onto a carbon-coated copper grid and was then dried at room temperature for transmission electron microscopy (TEM) analysis. The sizes of the nanotubes were determined directly from the figure using an Image - ProPlus 4.5 software. The value is an average size of five parallels.

\subsubsection{Ultrastructural Studies Using Scanning Electron Microscope (SEM)}

According to Nallamuthu et al. [11]; a GSM 610 LV Scanning Electron Microscope was used to make surface and subsurface (up to $5 \mu \mathrm{m}$ ) morphology. About $20 \mathrm{mg}$ CNT sample was coated with 40 - $60 \mathrm{~nm}$ of gold using ion sputter and then examined with Scanning electron microscope at an accelerating voltage of $30 \mathrm{kV}$ (GSM, EM. Mansoura University).

\subsubsection{Electron Diffraction Analysis}

Electron diffraction (ED) was performed to determine the structure of prepared carbon nanotubes. In selected area electron diffraction, a parallel beam is used to illuminate the specimen and the diffraction pattern that is formed in the back focal plane consists of sharp spots. In this method the region of interest is selected by inserting an aperture in the first image plane of the objective lens (the selected-area aperture). When a focussed, convergent beam illuminates the specimen the diffraction pattern consists of discs. The area from which the diffraction information comes is that illuminated by the electron beam $[12,13]$. All CNT diffraction patterns were obtained using a JEOL 1010 transmission electron microscope (JEOL, Mansoura University).

\subsubsection{Measurement of Zeta Potential of CNTs Either Alone or Loaded with NPK}

The zeta potentials of CNTs either alone or loaded with NPK were measured on zeta sizer (Malvern Instruments Ltd, EM. Mansoura University). The zeta cell should be washed by water followed by ethanol and finally by water again, dried using a gentle stream of nitrogen to remove any remaining solvent and then was covered to prevent any dust contamination. The CNTs samples were inserted to the zeta cell by gently depressing by using $1 \mathrm{~cm}^{3}$ syringe. About three runs for each sample were performed to create measurement repeatability. The applied voltage was set automatically [14].

\subsubsection{FT-IR Analyses of CNTs Either Alone or Loaded with NPK}

The FTIR measurements were performed by mixing $3 \mathrm{mg}$ of sample with $100 \mathrm{mg} \mathrm{KBr}$ (spectrally pure), then were pressed for 10 min under vacuum, forming a grayish round disk and measured on a Fourier transform spectrometer (NICOLET IS10 FT-IR instrument) [15].

\section{Results and Discussion}

\subsection{Preparation of Carbon Nanotubes}

Graphite powders are usually used as raw materials for bulk production of graphene sheets. Potassium chlorate with fuming nitric acid and sulfuric acid have been used to oxidize graphite into graphene oxide; nitric acid has been reacted with aromatic carbon surfaces which resulted in various oxygenated functional groups such as carboxyls, lactones, ketones, in carbon nanotubes and meanwhile, releasing of toxic gases like $\mathrm{NO}_{2}$ and $\mathrm{N}_{2} \mathrm{O}_{4}$. Also, potassium chlorate provides its oxidation capability by in situ generating dioxygen that is very reactive $[16 ; 17 ; 18]$.

CNTs show higher adsorption capacity due to their highly porous and hollow structure, large specific surface area, hydrophobic surfaces and strong interaction between CNTs and fertilizers molecules [19]. Their adsorption ability is attributed to (i) presence of high energy adsorption sites, such as CNT defects, functional groups, and interstitial and groove regions between CNT bundles. These adsorption sites commonly exist on as-grown CNTs [20]; (ii) condensation, such as surface and capillary condensation of gas or liquid adsorbates [21]. So, when the fertilizers were dissolved in 
water, cation and anion were developed then they were absorbed in the CNTs surface.

\subsection{Characterization of the CNTs and CNTs Loaded with NPK Fertilizers}

\subsubsection{Physical Characterization}

(i) Shape and structure of CNTs

To characterize the shape and structure of prepared CNTs, GSM 610 LV Scanning Electron Microscope (SEM) was used. As shown in figure 1a, CNTs had sharp edges and exhibit several sheets.

(ii) Morphology and size of CNTs and CNTs loaded with NPK fertilizers

TEM micrographs were taken to investigate the morphology of the prepared CNTs. In figure $1 \mathrm{~b}$; long and stripe-like CNTs are distinctly visible. The diameter of CNTs increase from 15.8 to $78.43 \mathrm{~nm}$ that indicated that the type of CNTs is multiwalled (MWCNTs).

Careful examination of figure $1 \mathrm{c}, \mathrm{d}$ and e reveals that the addition of $\mathrm{N}, \mathrm{P}$ or $\mathrm{K}$ to nanotubes solution leads to increase the sizes of nanotubes. The maximum increase in the mean diameter was $186.13 \%$ with the addition of phosphorus due to the formation $\mathrm{H}_{2} \mathrm{PO}_{4}^{-}$and $\mathrm{PO}_{4}{ }^{2-}$ groups of calcium phosphate, $66.71 \%$ with nitrogen due to deformation of ammonium ions $\left(-\mathrm{NH}_{4}^{+}\right)$and $27 \%$ with the addition of potassium due to the dissociation of $\mathrm{KCl}$ producing $\mathrm{K}^{+}$ions.

(iii) Structure of CNTs

Electron diffraction is the most direct and fast technique that gives access to detailed information about the structures of carbon nanotubes [3]. The electron diffraction pattern indicates that the tube has nearly identical chirality for all of the concentric graphitic layers, as a zigzag-type MWCNT. Figure 1f show that the diffraction configurations exhibit rotation crystal patterns. Rings and spots indicating that the nanotubes contain zigzag edges and are crystallized.
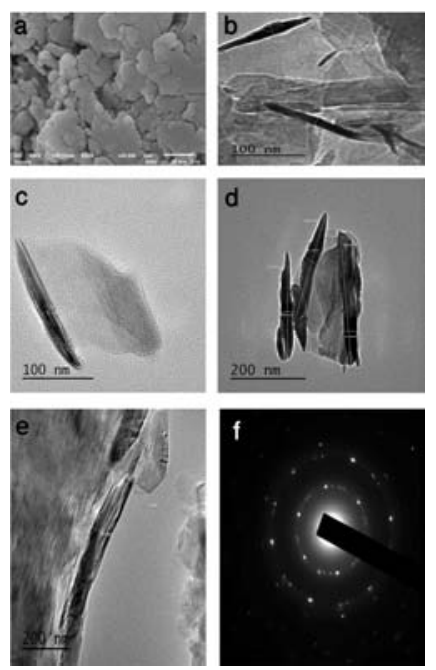

Figure 1. a-SEM micrograph of the CNTs, b-TEM micrograph of carbon nanotubes (CNT), c- TEM micrograph obtained for carbon nanotubes (CNT) loaded with urea $\mathrm{CNT}-\left(\mathrm{NH}_{2} \mathrm{CONH}_{2}\right), d$ - TEM micrograph obtained for carbon nanotubes (CNT) loaded with potassium chloride CNTs- $(\mathrm{KCl})$, eTEM micrograph obtained for carbon nanotubes (CNT) loaded with calcium phosphate ((CNT-(Ca $\left.\left.\left(\mathrm{H}_{2} \mathrm{PO}_{4}\right)_{2}\right)\right)$, - Electron diffraction pattern of CNTs.

\subsubsection{Chemical Characterization}

(i) Zeta potential $(\zeta)$

Table 1 and figure 2 indicate the value of zeta potential ( $\mathrm{z}$ $\mathrm{p} \zeta$ ) of CNTs either alone or in combination with $\mathrm{N}, \mathrm{P}$ or K fertilizer according with the changing $\mathrm{pH}$; It was found that for CNTs loaded with nitrogen $(\mathrm{N})$, the zeta potential value

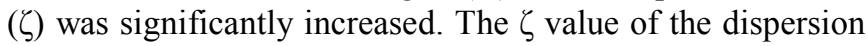
of CNTs loaded with phosphorus (P) was lower when compared to the $\zeta$ value of pure CNTs, and for the dispersion of CNTs loaded with potassium (K). According to the DLVO (Derjaguin-Landau-Verwey-Overbeek) theory, a potential between charged particles in suspension may result in colloidal meta-stability due to the van der-waals forces and repulsion caused by the overlap of the electric double layer around each particle [22].

The MWCNTs may possess negative or positive charge on their surface, depending if the surrounding media used is a cationic or anionic. The zeta potential is used to study the stability of carbon nanotubes. CNTs solution is more sensitive to change in the $\mathrm{pH}$ of medium and negative values of the zeta potential indicate that the CNTs are negatively loaded. This difference in the zeta potential values depending on the medium $\mathrm{pH}$ is attributed to the energy electrical field in the CNTs surface surrounded by another ion [23]. The zeta potential increase gradually, with the addition of NPK fertilizer due to the absorption of negative and positive charge on the surface of carbon nanotubes.

(ii) FT-IR analyses

FTIR is used to study spectral changes in position or shape occurred in the distribution of frequencies which used to identify the presence of functional group absorbed by carbon nanotubes. In the measured IR absorbance spectrum, a prime intensity peak is seen at $1584 \mathrm{~cm}^{-1}$. This is an IR-active, graphite originating from the $\mathrm{sp}^{2}$ hybridized carbon [24]. Peaks at 2915 and $2854 \mathrm{~cm}^{-1}$ are caused by $\mathrm{C}-\mathrm{H}$ vibrations of alkyl group which are a residue of hydrocarbon molecules used for growing the CNTs. The band at $3434 \mathrm{~cm}^{-1}$ can be attributed to vibrations of $\mathrm{O}-\mathrm{H}$ bonds in hydroxyl and carboxyl groups formed upon the oxidation of the nanotubes, the absorption peaks at 1573 and $1634 \mathrm{~cm}^{-1}$ can be attributed to $>\mathrm{C}=\mathrm{O}$ groups.

IR spectrum of the CNTs oxidized with nitric acid is characterized by the presence of absorption bands corresponding to $\mathrm{C}-\mathrm{H}\left(2923,2854\right.$ and $\left.1462 \mathrm{~cm}^{-1}\right),>\mathrm{C}=\mathrm{C}<$ $1636 \mathrm{~cm}^{-1}$, and $\mathrm{O}-\mathrm{H}\left(3450 \mathrm{~cm}^{-1}\right)$ bonds. The absorption band corresponding to the $\mathrm{C}=\mathrm{O}$ bond vibration in the carboxyl $\left(1739 \mathrm{~cm}^{-1}\right)$ in the IR spectrum of the boiling nitric acid oxidized CNTs, has a very low intensity. This peak was more pronounced for the material oxidized with nitric acid vapor. Thus, the IR data indicated that treatment of the CNTs with nitric acid vapor resulted in much more deep oxidation [25].

The presence of $\mathrm{C}-\mathrm{N}$ and $\mathrm{N}-\mathrm{CH}_{3}$ bonds at $1391 \mathrm{~cm}^{-1}$ is attributed to the presence of intercalated $\mathrm{N}$ atoms between the graphite layers at the inner part of the nanotube walls however, may not be strongly IR active [26]. 
Mohammed Nagib Abdel-Ghany Hasaneen et al: Characterization of Carbon Nanotubes Loaded with Nitrogen, Phosphorus and Potassium Fertilizers

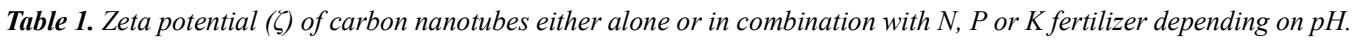

\begin{tabular}{lllll}
\hline PH & CNT & CNTs- N & CNTs- P & CNTs-K \\
\hline 1 & -5.70 & -2.19 & -1.13 & -0.075 \\
1.5 & -11.7 & -10.00 & -8.2 & -5.57 \\
2 & -15.3 & -10.6 & -10.2 & -9.84 \\
2.5 & -11.7 & -4.68 & -3.8 & -3.64 \\
3 & -8.32 & -8.30 & -8.35 & -8.40 \\
\hline
\end{tabular}

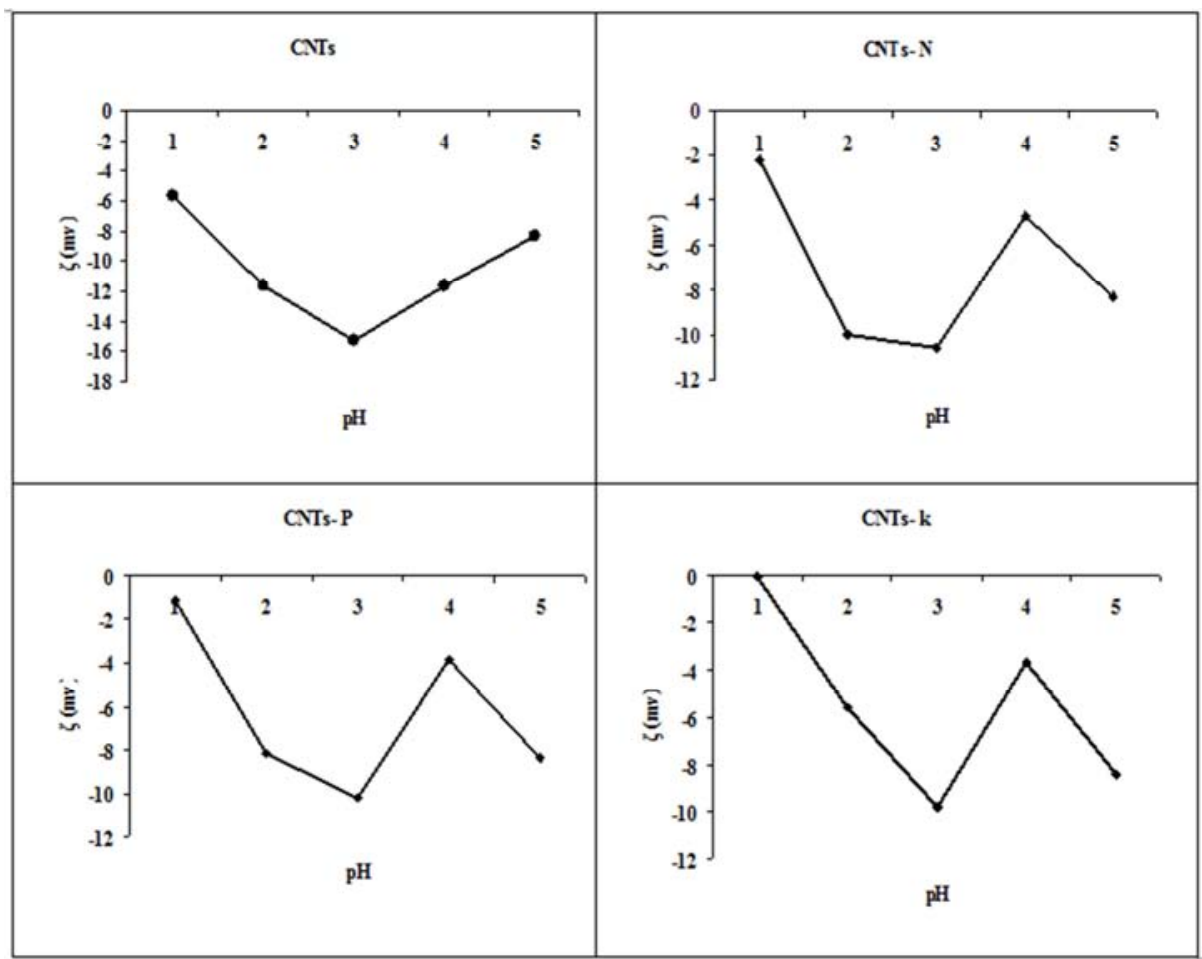

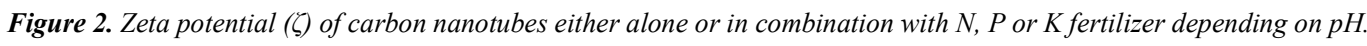

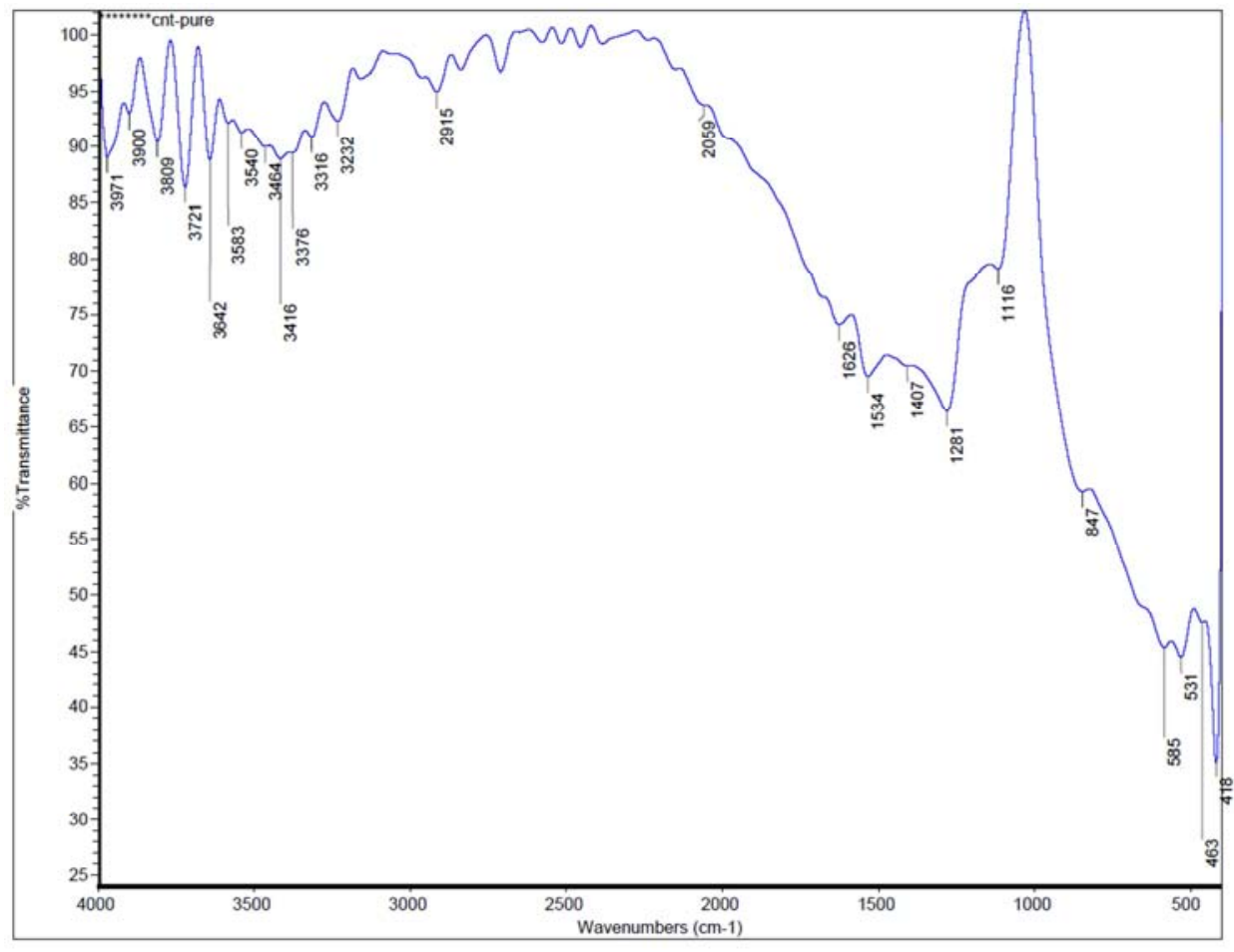

Figure 3. IR spectrum of pure solid CNTs. 


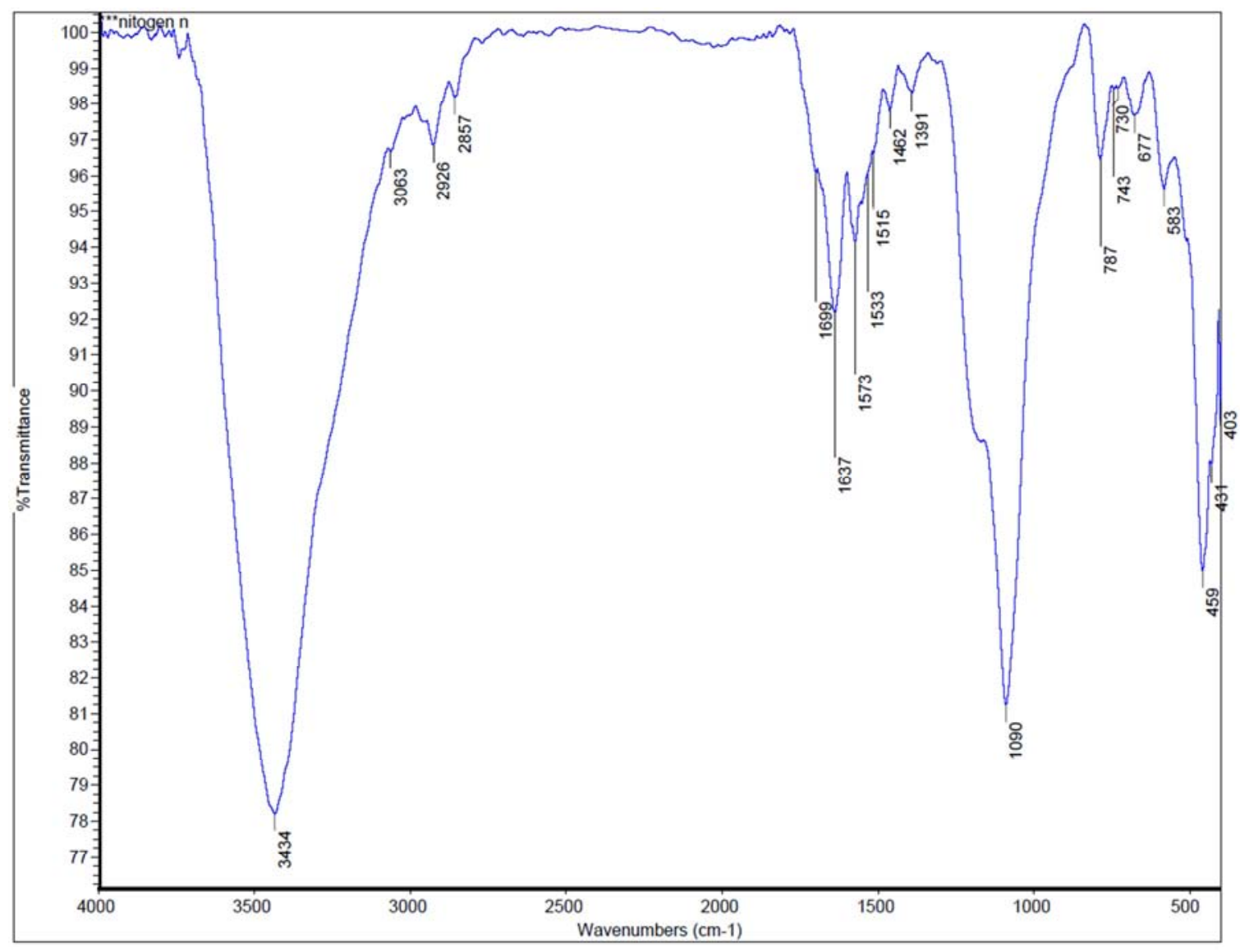

Figure 4. IR spectrum of for carbon nanotubes (CNT) loaded with urea $\mathrm{CNT}-\left(\mathrm{NH}_{2} \mathrm{CONH}_{2}\right)$.

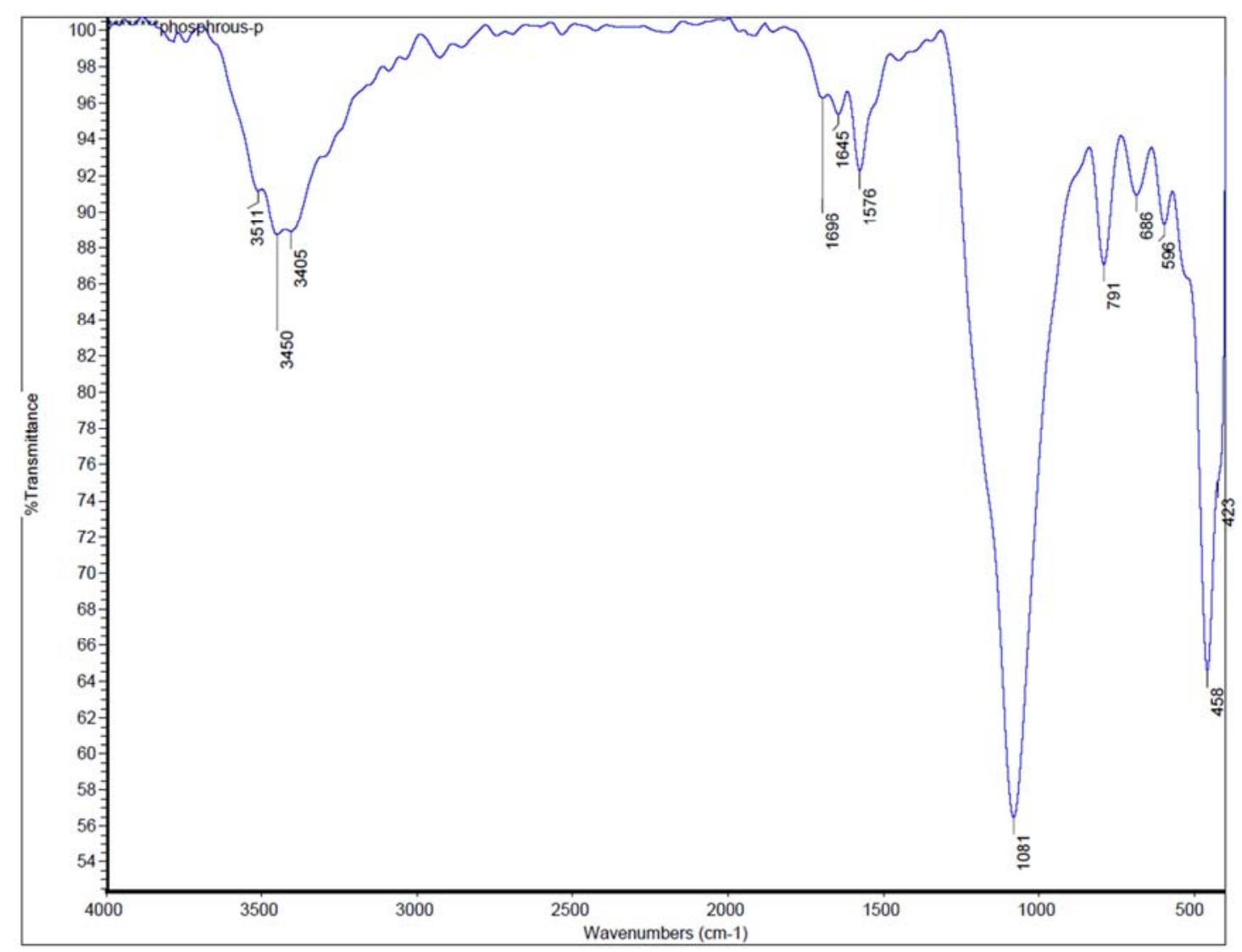

Figure 5. IR spectrum of for carbon nanotubes (CNT) loaded with calcium phosphate ((CNT-(Ca $\left.\left.\left(\mathrm{H}_{2} \mathrm{PO}_{4}\right)_{2}\right)\right)$. 


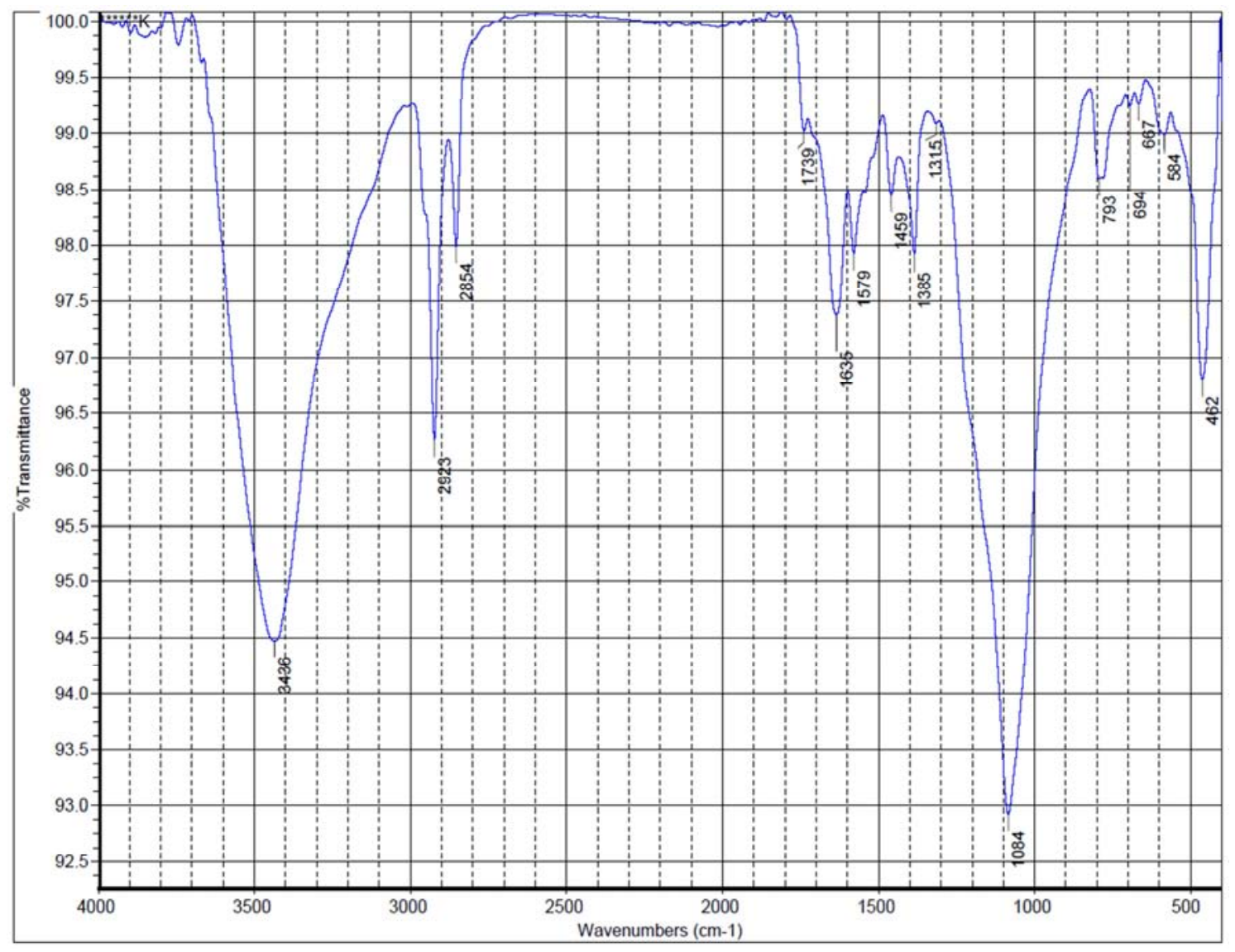

Figure 6. IR spectrum of for carbon nanotubes (CNT) loaded with with potassium chloride CNTs- (KCl).

\section{Conclusion}

From the provided results it is apparent that CNT have been loaded successfully with nitrogen, phosphorus and potassium which open a wide array of uses to such CNTs. The amazing findings here within can contribute to the use of such loaded CNTs as slow release fertilizers which could open up new era of agricultural uses and practices.

\section{References}

[1] Popov, V. N. (2004). Carbon nanotubes: properties and application. Materials Science and Engineering, 43: 61-102.

[2] Endo, M. (1975). Mecanisme de croissance en phase vapeur de fibres de carbone. PhD thesis, University of Orleans, France.

[3] Iijima, S. (1991). Helical microtubules of graphitic carbon. Nature, 354: 56-58.

[4] Qiu, J.; Li, Y.; Wang, Y. and Li W. (2004). Production of carbon nanotubes from coal. Fuel Processing Technology, 85: $1663-1670$.

[5] Dai, H.; Kong, J.; Zhou, C.; Franklin, N.; Tombler, T.; Cassell, A.; Fan, S. and Chapline, M. (1999). Controlled chemical routes to nanotube architectures, physicsand devices, Journal of Physical Chemistry, 103: 11246-11255.
[6] Dai, H. (2002). Carbon nanotubes: synthesis, integration, and properties. Accounts of Chemical Research, 35: 1035-1044.

[7] Lal, R (2008). Soils and India's food security. Journal of the Indian Society of Soil Science, 56: 129-138.

[8] Jinghua, G. (2004). Synchrotron radiation, soft X-ray spectroscopy and nano-materials. Journal of Nanotechnology, 1: $193-225$.

[9] Lee, D. W. and Seo, J. W. (2011). Preparation of carbon nanotubes from graphite powder at room temperature. http://arxiv.org/pdf/1007.1062.

[10] Hasaneen, M. N. A.; Abdel-Aziz, H. M. M.; El-Bialy; D. M. A. and Omer, A. M. (2014). Preparation of chitosan nanoparticles for loading with NPK. African Journal of Biotechnology, 13: 3158-3164.

[11] Nallamuthu, I.; Devi, A. and Khanum, F. (2015). Chlorogenic acid loaded chitosan nanoparticles with sustained release property, retained antioxidant activity and enhanced bioavailability. Asian Journal of pharmaceutical Science, 10: 203- 211

[12] Steeds, J. W. (1981). In Quantitative Microanalysis with High Spatial Resolution, The Metals Society, London, 210.

[13] Champaness, P. E. (1987). Convergent beam electron diffraction. Mineralogical Magazine, 51: 33-48.

[14] Frederick, M. D (2009). Measuring Zeta Potential of Nanoparticles. Nanotechnology Characterization Laboratory. http://104.154.93.228/the-national-cancer-institute-atfrederick.Pdf. 
[15] Trykowski, G.; Biniak, S.; Stobinski, L. and Lesiak, B. (2010). Preliminary Investigations into the Purification and Functionalization of Multiwall Carbon Nanotubes. Acta Physica Polonica, 118: 515-518.

[16] McCleverty, J. A. (1989). Advanced inorganic chemistry, 5th edition cotton, fa, Wilkinson, G. Nature, 338: 182-182.

[17] Becker, L.; Poreda, R. J. and Bunch, T. E. (2000). Fullerenes: An extraterrestrial carbon carrier phase for noble gases. Proceedings of the National Academy of Sciences of the United States of America, 97: 2979-2983.

[18] Rosca, I. D.; Watari, F.; Uo, M. and Akasaka, T. (2005). Oxidation of multiwalled carbon nanotubes by nitric acid. Carbon, 43: 3124-3131.

[19] Wang, W.; Jiang, C.; Zhu, L.; Liang, N.; Liu, X.; Jia, J.; Zhang, C.; Zhai, S. and Zhang, B. (2014). Adsorption of Bisphenol A to a Carbon Nanotube Reduced Its Endocrine Disrupting Effect in Mice Male Offspring. International Journal of Molecular Science, 15: 15981-15993.

[20] Li, Y.; Chen, X. and Gu, N. (2008). Computational investigation of interaction between nanoparticles and membranes: hydrophobic/hydrophilic effect. Journal of Physics, Chemistry and Botany, 112(51): 16647-16653.

[21] Fagan, S. B.; Souza, A. G.; Lima, J. O. G.; Mendes, J.; Ferreira, O. P.; Mazali, I. O.; Alves, O. L. and Dresselhaus, M.
S. (2004). 1,2- dichlorobenzene interacting with carbon nanotubes. Nanotechnology Letters, 4: 1285-1288.

[22] Labidi, N. S. and Djebaili, A. (2008). Studies of the mechanism of polyvinyl alcohol adsorption on the calcite/water interface in the Presence of sodium oleate. Journal of Minerals and Materials Characterization and Engineering, 7: 147-161.

[23] Cruz, E. F.; Zheng, Y.; Torres, E.; Li, W.; Song, W. and Burugapalli, K. (2012). Zeta Potential of Modified Multiwalled Carbon Nanotubes in Presence of poly (vinyl alcohol) Hydrogel. International Journal of Electrochemical Science, 7: 3577-3590.

[24] Kouklin, N.; Tzolov, M.; Straus, D.; Yin, A. and Xua, J. M. (2004). Infrared absorption properties of carbon nanotubes synthesized by chemical vapor deposition. Applied Physics Letters, 85(19): 4463-4465.

[25] Dyachkova, T. P.; Melezhyk, A. V.; Gorsky, S. Yu.; Anosova, I. V. and Tkachev, A. G. (2013). Some aspects of functionalization and modification of carbon nanomaterials. Nanosystems: physics, chemistry, mathematics, 4 (5): 605621.

[26] Misra, A.; Tyagi, P. K.; Rai, P. and Misra, D. S. (2007). FTIR Spectroscopy of multiwalled carbon nanotubes: a Simple approachto study the nitrogen doping. Journal of Nanoscience and Nanotechnology, 7 (6): 1820-1823. 